\title{
Legal Principles of Environmental Accounting as Means of Identifying Sustainable Development Indicators in Ukraine
}

\author{
Volodymyr Yermolenko을 Olena Gafurova $^{2}$, Mariya Krasnova ${ }^{3}$, Yuliia Krasnova ${ }^{4}$
}

\begin{abstract}
The article presents the results of the legal analysis of the formation of environmental accounting as one of the main means of determining the effectiveness of the implemented indicators of sustainable development. It is established that today there are no common approaches around the world to identify sustainable development indicators, including their environmental component. This greatly influences the development of a unified system of environmental accounting, which contains important data on the quantity and quality of natural resources, their legal status, the number of objects and substances that have harmful effects on the environment, financial and other measures taken for the environmental modernization of enterprises, the payment of environmental payments, etc., as such information is a major factor in making further management decisions to achieve sustainability in the environmental field, both locally, nationally, regionally, and globally. tovomu level.
\end{abstract}

Keywords: sustainable development, indicators, ecological accounting, ecological information, reliability of data, types of ecological accounting systems, systematization of ecological accounting systems, regulatory legal regulation of ecological accounting.

\section{Introduction}

The increasing level of environmental pollution, the growth of natural and manmade disasters, the depletion of natural resources make the importance of solving the problems of protection and protection of the environment, the conservation and rational use of natural resources. That is why the state and the environment are becoming more relevant to human development. Not so much the traditional political and socioeconomic problems as the pressing environmental problems are becoming increasingly active. They are caused by both nature and human activity, with the latter being more noticeable.

In such circumstances, it becomes obvious that there is a vital need to solve the problems of optimization of environmental management, rehabilitation and environmental protection. Developing a sound state policy on natural resources,

\footnotetext{
| ${ }^{1}$ Doctor of Law, professor, head of the Department of Agrarian, Land and Environmental Law named after Academician V. Yanchuk of the National University of Life and Environmental Sciences of Ukraine. ${ }^{2}$ Doctor of Law, professor, professor of the Department of Agrarian, Land and Environmental Law named after Academician V. Yanchuk of the National University of Life and Environmental Sciences of Ukraine.

${ }^{3}$ Doctor of Law, professor, professor of the Department of Agrarian Law of Taras Shevchenko National University of Kyiv.

${ }^{4}$ Doctor of Law, associate professor, associate professor of the Department of Agrarian, Land and Environmental Law named after Academician V. Yanchuk of the National University of Life and Environmental Sciences of Ukraine.
} 
environmental security and environmental protection is required. In this regard, there is a growing need for a significant restructuring of environmental accounting, which generates, analyzes and publishes information on these important issues, and serves as an information base for the preparation and decision making of environmentally sound decisions. At the same time, it is an important and effective link to modern governance in the context of the transition to sustainable socio-economic development declared at the United Nations Conference on the Environment (Rio de Janeiro, 1992) and endorsed at the World Summit in Johannesburg (2002). ), the Fifth Pan-European Conference of Ministers of the Environment «Environment for Europe» (Kyiv, 2003), the UN World Summit on Sustainable Development (2015), etc., as it contains important data on the environmental status of the speakers Th indicators of the environmental component of sustainable development.

Constructive analysis of scientific results in this subject area allows us to draw conclusions about the materiality of theoretical and methodological scientific developments. At the same time, we find that the issue of establishing environmental accounting as a means of determining sustainable development indicators has not been investigated in both domestic and foreign legal science, and therefore the purpose of this article is to study the existing experience of foreign countries in the formation and operation of such accounting systems to choose the best option for creating your own environmental accounting system that will help ensure sustainability in the environment.

\section{The legal nature of environmental accounting as a means of determining indicators of sustainable development}

Sustainable development not only of the state as a whole, but of any region combines three main components - economic, social and environmental. An important problem in the implementation of the concept of sustainable development is the creation of a measurement system for quantitative and qualitative evaluation of this very complex process, the main requirements of which are the informative completeness and adequacy of the presentation of the interconnected triad of components of sustainable development. The development of sustainable development indicators is a complex and expensive procedure (Indicators of Sustainable Development of Russia, 2001). The large number of indicators in the system complicates their use in many countries due to the lack of necessary statistics. A sustainable development indicator should be considered a quantitative indicator that can reflect economic, social and environmental development in a particular region and has such features as ease of interpretation, wide scope, sensitivity to change, quantification, and making forecasts and timely trends.

Controlling the achievement of the Sustainable Development Goals, managing this process, making decisions, evaluating the effectiveness of the tools used, and the level of achievement of the objectives set, require the development of appropriate criteria and indicators - indicators of sustainable development. Thus, the main purpose of creating a system of indicators is to monitor the sustainable development of society. Recently, significant work in the field of indicator development has been carried out by a number of collectives at the local, regional and global levels of both sustainable development in general and its individual aspects (Pirikov, 2013; Nesterenko, 2017; Garcia, Staples, and 
Chesson, 2000; Kuik and Verbruggen, 2012; Steurer and Hametner, 2010; Schaltegger and Burritt, 2000 etc.).

Several options for assessing sustainable development are already being actively developed and are already under way in the world community, the most well-known being a System for Integrated Environmental and Economic Accounting (SIEEA), which aims to take environmental factors into account in national statistics.

The system shows the relationship between the state of the environment and the economy of the state (the relationship is expressed through the UN system of national accounts taking into account environmental factors and natural resources).

This system includes not only environmental monitoring data, but also information on the environmental performance of enterprises (purchase and use of natural resources, emissions, discharges and disposal of waste, costs of post-emergency measures, including compensation for environmental damage, etc.). Such a system is called ecological accounting (Kozhukhova, 2012; MacGillivray and Zadek, 1995; Carlos LarrinagaGonzalez and Bebbington, 2001; O’Donovan, 2001; Jones, 2019).

In this regard, environmental accounting (in the general economic sense) is defined as a system for detecting, measuring, registering, accumulating, summarizing, storing, processing and preparing relevant information about an enterprise's activity in the field of environmental management for the purpose of transmitting it to internal and external users for making optimal decisions (Kirsanova, 2004).

Based on the same principles as all accounting systems, the environmental accounting system provides an objective picture of the state and dynamics of natural heritage, the interaction between the economy and the environment and the costs of preventive measures, environmental protection and environmental damage.

Thus, environmental accounting is the most important tool for implementing the concept of sustainable development, that is, development that does not destroy the resources necessary for the life and development of future generations on Earth. Without reliable and complete information on the state of the environment it is impossible to speak about the proper implementation of other environmental rights of the individual (Golovko, 2019; Ladychenko 2019).

In recent years, the increasing impact of human activity on the environment at the local and global levels has clearly demonstrated that the environmental costs of the development process can no longer be simply ignored, especially in urban areas, and that specific tools should be used to assess and regulate them.

In addition, increased access to information has made environmental data increasingly in demand for policymakers and ordinary citizens alike, which necessitates better regulation of environmental performance. Information support in the field of environmental protection is one of the main elements of the state's obligation to create favorable conditions for life and health of people (Ladychenko, 2018; Yara, 2018).

Therefore, legal science has found that environmental accounting combines the information function and the function of environmental management, it is usually associated with natural resources, where such a function, in turn, is defined as the collection and analytical summation of information about the quantity and quality of available natural resources for organization of their rational use, planning of economic and environmental activities, forecasting trends in the development of environmental 
industries and changes in the environment in the current period and in the future (Lazareva and Milovets, 2008). Calling ecological accounting a system of accounting for environmental activities (Shapinguzov, 1997).

Today, such accounting also performs its own functions: 1) optimistic, which is to create the grounds for the best choice of optimal options for environmentally-friendly activities; 2) motivational, which is manifested in providing information to stimulate the implementation of solutions to environmental problems; 3) controlling, which is to carry out control measures for the implementation of environmental costs (Gritsenko, 2016). In this regard, in the environmental legal literature, such accounting is attributed, in addition to the function of environmental management, to the type of environmental information (Brynchuk, 1998).

In Ukrainian environmental law, such accounting is defined as environmental accounting, which includes accounting for natural resources and accounting for objects and substances that adversely affect the state of the environment (Malysheva, 2018). We propose to consider it as a means of ensuring environmental safety, regulated by the system of legal norms, which is realized within the limits of ecological relations, through the purposeful activity of specially authorized state and self-governing bodies, institutions, organizations and economic entities, the purpose of which is to collect, process and submit a summary statistical reporting on the amount of natural resources available in the state that are conserved, as well as those owned or used and their condition; the amount of emissions and discharges of pollutants, as well as the development, review, analysis and evaluation of technical and regulatory documents ecological passport of the enterprise, safety declaration or passport of waste, etc., which allows to establish the level of environmental risk of various types of substances and objects to the requirements of ecological safety and entering them to special state (sectoral) registers (cadastres), which are one of the instruments for preventing emergencies of anthropogenic and natural nature, and therefore an indicator of ecology term component of sustainable development.

In fact, in Ukraine today there are such types of environmental accounting (excluding natural resources inventories), such as:

1) state registration in the field of atmospheric air protection, which includes maintenance of: State register of pesticides and agrochemicals authorized for use in Ukraine, State register of veterinary preparations, feed additives, premixes and finished feeds, National inventory of anthropogenic emissions and absorption of steam;

2) state registration of hazardous factors (chemical, physical and biological), by keeping such registers as: State register of dangerous factors; State Register of Ionizing Radiation Sources; Dose irradiation registry; Single registry of licenses issued for conducting activities in the field of nuclear energy use; Register of radio electronic devices and radiation devices that may be used in the territory of Ukraine in the bands of public radio frequencies; State register of genetically modified organisms of varieties of agricultural plants in an open system; State register of cosmetics and medicines containing or derived from genetically modified organisms;

3) accounting for discharge of return (waste) water and pollutants, which today has no special legal regulation and is a component of a more general state accounting accounting of water use; 
4) state registration of objects that have an adverse impact on the environment, within which the state register is kept: State register of potentially dangerous objects, State register of high-risk objects, State register of economic entities carrying out the acceptance and / or dismantling of vehicles, disposed of, State cadastre of radioactive waste repositories, Register of waste disposal, treatment and disposal facilities and Register of waste disposal sites. In case of emergencies at such sites, the State Emergency Service of Ukraine shall also keep records of such emergencies.

The diversity of existing types of environmental accounting in Ukraine, on the one hand, confirms the active participation of the state in controlling the level of environmental pollution in its territory, and on the other - defines the need to integrate existing accounting systems into a single, more general, able to comprehensively determine the state of the environment in the state.

To find out this possibility, let us turn to the world practice in the formation of similar databases.

\section{Legal principles of formation of ecological accounting at the international and foreign level}

It should be noted that initially accounting was not perceived as an environmental management tool, despite the rapid increase in costs and responsibilities of foreign enterprises associated with environmental protection - they were not reflected in the financial statements. The first attempts to reflect environmental parameters in the enterprise accounting and reporting system began to be made in the 1970s (International Standards, 1998; Kovalyov, 1997).

In particular, the First International Conference on Environment, convened by the United Nations (hereinafter referred to as the UN), took place in Stockholm in 1972. In accordance with its decisions, a program, UN recommendations on common environmental issues, sustainable nature management and environmental protection of a planetary nature have been developed.

Based on this program, the Statistical Office of the Secretariat of the United Nations, after extensive consultations with other international organizations, relevant governments in many countries of the world conducted a study of the problem: what should be the system of environmental indicators, the need for environmental statistics, what methods of its collection and processing, etc. A guide to environmental statistics and a framework (recommendations) for the development of environmental statistics (hereinafter referred to as the FDES) for international environmental and statistical organizations and individual countries has been prepared. For the first time, the Statistics Office of the UN Secretariat has defined the environment statistics as a field of general statistics (Framework for Development, 1985).

FDES covered the six major components of the environment: the atmosphere, water (fresh and marine), land (surface and subsoil), flora, fauna and settlements. Each of these components was considered in the light of four categories of information: socioeconomic activity of people and natural phenomena; the effects of these activities and phenomena on the environment; the reaction of society to them; baselines, fixed assets and stocks. 
FDES have become the basis for organizing environmental statistics in each country and for interested international organizations. And although they have absorbed some of the experience of some countries, the work of international statistical and environmental organizations, they have not yet been able to act as a complete international form. After all, there were no generally accepted theoretical foundations and standards, common, common units of calculus, etc. The RSRSS were indeed of a recommendatory nature (Kolesnik, 2000; Concepts and Methods, 1992). Therefore, in 1974, at the eighth session of the EU Statistical Commission, the United Nations Secretariat-General's Program for International Activities in the Field of Environmental Statistics, proposed by the Statistical Office of the United Nations, was considered.

At the same time, in the early 70 -ies of the twentieth century, a complex environmental situation emerged around nature-using enterprises, which are the main pollutants of the environment: on the one hand, public protests against environmentally harmful activities intensified, on the other - intensified, on the other stringent environmental requirements, the failure of which entailed very strict liability measures up to the closure of the enterprise. For example, violating the water quality standards of the U.S. Clean Water Act (as amended in 1972, 1977, and 1987) entailed criminal, civil, and administrative liability. For particularly serious offenses the court was fined $\$ 2.5$ to $\$$ 25,000 for each day of the violation and (or) imprisonment for one year. For less serious offenses fined up to 10 thousand dollars for each day of violation. Administrative responsibility was the right of the Environmental Protection Agency to issue a notice of a registered violation requesting its termination, as well as the right to enter the offending company in the lists of persons with whom federal contracts are terminated or federal aid is terminated. In the highly competitive US market, such administrative sanctions are extremely effective: it discredit the firm, threaten to lose its clientele, and for some entrepreneurs, contract termination or denial of federal aid means financial collapse. Thus, business entities had to urgently take preventative measures to address the situation that threatens their financial ruin (Krasnova, 1992).

For example, at one time, the US Environmental Protection Agency identified 27,000 landfills that required $\$ 1$ billion to clean up. However, this did not happen and the costs were not included in the financial statements of the entities responsible. Most enterprises generally refused to acknowledge the extent of their environmental pollution action and to consider the cost of waste treatment, as this would reflect the value of their shares (Serov, 1999).

Subsequently, many businesses in Europe and North America became legally liable for damaging the environment, causing additional financial loss for them. In this regard, the enterprises began to evaluate the compliance of their activities with the environmental legislation within the newly created function of environmental audit (Concept, sources et methods, 2006).

For example, the adoption in 1976 of the Resource Conservation and Restoration Act in 1976 and the Comprehensive Environmental Protection, Compensation, and Liability for Pollution Act in 1980 led to private sector companies implementing environmental audit programs with to reduce costs and avoid liability that may result from failure to comply with environmental requirements (Environmental Audit Program, 1997). 
With regard to the public sector, the use of environmental audit was initially sporadic. For example, since the 1970s, the French Ministry of the Environment has submitted reports on public expenditures in the following areas: aspen - cleaning; air; noise; waste; street cleaning; environmental heritage; research and development; environmental management (Gruning and Cohen, 2000).

For the first time at the local regulatory level, environmental accounting issues were introduced in Germany in 1973 by developing Guidelines on methods for calculating the volume of costs associated with environmental activities at chemical enterprises, based on the recommendations of the Economics Division of the German Chemical Industry Association (Verband der Chemischen Industrie e.v.) (Matveeva, 1998).

In 1974, the Norwegian Environmental Accounting System was developed with a detailed structure and the necessary information base of accounts for economically strategically important resources, such as oil, gas, electricity, as well as for the volume of emissions into the atmosphere. The system was aimed at reflecting the flows of such substances (Matveeva, 1998).

An attempt to develop an expanded environmental accounting system was made in 1976 in Canada. In the same period, France developed a «System of accounting for the natural heritage», which includes information about all the natural resources of the country under the scheme «initial stocks» - «final stocks» - «natural renewal» - «net accumulation» or «annual, possible volume consumption» - «available resources»). These include: impact on the functioning of the natural environment; extraction (use) of natural resources; development of territories; the impact of pollutant emissions and waste production; types of economic activity that pollute the environment, etc. (Grüning and Cohen 2000, 4). In 1986, such a system of data included: a) continental water management (19751983); b) waste disposal and recycling (1978-1983); c) protected natural spaces (national parks (1974-1983), regional parks (1975-1980)); d) protection of marine areas (1982); e) hunting (1983) (Gruning and Cohen, 2000).

Since 1978, the United States of America (New Jersey) has for the first time created a Pollutant Emissions Register, which has included 155 chemicals and 7,000 reporting organizations. The obligation to maintain such a register by all US businesses was enshrined in 1986 in the US Comprehensive Environmental Protection, Compensation and Liability Act after the Bhopal disaster.

In addition, since 1984, the United States and Canada have for the first time created a system of economic and environmental auditing to gather information on the peculiarities of the harmful effects of various areas of human activity on the environment (Yegorova, 1995).

However, ecological accounting has received special attention from the international community only since the early 1990s.

In 1991, International Society for Astrological Research (hereinafter referred to as ISAR) developed the first guidance (guidance) for accountants to reflect in the financial statements the environmental impact of an entity's business activities (Tax System, 1997). The work on environmental accounting has quickly spread to other international and national organizations. For example, the Organization for Economic Cooperation and Development, the European Commission, the Canadian Institute of Chartered Accountants, the Chartered Accountants Association and the Chartered Accountants 
Institute of England and Wales have raised environmental issues for joint discussion. ISAR reviewed the development of environmental accounting in different countries to develop guidance for standard setting bodies (Tax system, 1997).

At the 1992 UN Conference on Environment and Development (Summit «Planet Earth» in Rio de Janeiro), the concept of environmental accounting was proposed as a tool for consistent policy on sustainable development.

In this case, environmental accounting was proposed to be considered as a system that can be used to detect, organize, regulate and submit data and information on the state of the environment in natural and value terms (Recommendations, 2004).

Based on the same principles as all accounting systems, the environmental accounting system should provide an objective picture of the state and dynamics of natural heritage, the interaction between the economy and the environment and the costs of preventive measures, environmental protection and the compensation of environmental damage (Parliamentary Assembly Recommendations Council of Europe, 2004).

Thus, environmental accounting was considered as one of the most important tools for the implementation of the concept of sustainable development, that is, such a development that does not destroy the resources necessary for the life and development of future generations on Earth. For example, the implementation of the Kyoto Protocol, as well as EU Directive 2003/87, which establishes a mechanism for trading greenhouse gas emission allowances, requires the introduction of a unified, reliable and well-tested accounting system.

In pursuit of this decision, the United Nations Statistics Division has published a Guide to National Accounts: System of Environmental Economic Accounting, commonly referred to as SEEA (System of Environmental Economic Accounting, 2001), which is based on the consideration of the environmental factor in national statistics and is based on adjustment of traditional economic indicators due to two values: estimation of the cost of natural resources depletion and ecological and economic damage from pollution. In 1993, under the auspices of the United Nations Statistics Commission, the London Group on Environmental Accounting was established as a forum for practitioners to share their experience in developing and maintaining natural and economic accounts. Expanding discussions on the concepts and methods of natural and economic accounting, together with the experience of individual countries, has led to a more active convergence of concepts and methods for different SEEA modules (Central basis, 2017). Based on materials prepared by the Nairobi Group (formed in 1995 as a panel of experts from national and international institutions and non-governmental organizations), in 2000, the United Nations Statistics Division and the United Nations Environment Program (UNEP) published a publication entitled «National Accounts Guide: integrated environmental and economic accounting. Operational Manual»(Central Basis 2017, 3). This publication, which reflected the ongoing discussion following the publication of SEEA in 1993, provided a step-by-step guide to the development of more practical SEEA modules, and outlined the possibilities of using integrated natural and economic accounting in the development of further environmental policies.

Therefore, already in 2003, the National Accounts Guide: A Comprehensive Environmental and Economic Accounting (SEEA-2003) was updated in terms of the 
breadth of coverage and unification of environmental accounting concepts, definitions and methods.

However, this document presents a number of different methodological approaches, as well as a wide range of examples that show the different practices of individual countries. As a result, SEEA-2003 has not been formally adopted as an international statistical standard but recognized as a stand-alone statistical system that, on the whole, has provided a widely recognized and reliable basis for compiling natural-economic accounts and has been used by many countries around the world.

Recognizing the ever-increasing importance of environmental information and the need to include this information in an economic context accessible to central decision-makers, the Statistical Commission agreed at its thirty-eighth session, held in 2007, to launch a second review process with a view to adopting SEEA as an international a statistical standard for natural-economic accounting over the next five years.

The result of this process was the adoption by the UN Statistical Commission of the Central Basis of the System of Natural and Economic Accounting in 2012 as an international standard (Central Basis, 2017).

«Central Basis of the Natural Accounting System» is a statistical toolkit that includes a comprehensive set of tables and accounts and is intended to guide the compilation of consistent and comparative statistics and metrics in policy development, analysis and research. It takes into account changes in the needs of its users, new developments in the field of natural and economic accounting and recent advances in methodology.

Examples of reports in the Natural Accounting System can be found on the SEEA website (https://unstats.un.org), in particular: 1) reports: «Nature and Wealth of Nations» (La Revue du CGDD, 2015); «CO2 Content in Import and Export of Germany, 2000-2010» (Umweltökonomische Gesamtrechnungen, 2014); «Waste Account, Australia, Experimental estimates» (Waste Account, 2013); «Extended InputOutput model for energy and greenhouse gases» (Extended Input-Output, 2011); «Manual for Air Emissions Accounts» (Manual for Air Emissions Accounts, 2015); «Accounting for Freshwater quality in India» (Accounting for Freshwater, 2007) (Green Accounting for Indian States Project, 2007), ets.

Today, the environmental accounting system takes into account the requirements of many international instruments in the field of environmental protection.

Confirmation of this is the United Nations Framework Convention on Climate Change with respect to the obligation to develop, periodically update, publish and submit to the Secretariat of the Convention national inventories of anthropogenic emissions from sources and removals by sinks of all non-regulated Montreal layer (hereinafter referred to as the Cadastre). Part 4 of Article 3 of the Kyoto Protocol therefore establishes the obligation to submit to the Subsidiary Body for Scientific and Technological Consultation data for determining the level of carbon accumulation in 1990 and for assessing changes in carbon accumulation in subsequent years, what according to the rules of Part 1 of Article 5 of the Kyoto Protocol should be established no later than one year before the start of the first commitment period for a national system for anthropogenic emissions from sources and removals by sinks of all greenhouse gases not regulated by the Montreal Protocol (hereinafter - the National System). 
Information on annual inventories after the inclusion of the provisions of Decision 14 / CP.11 (2006) provide that the inventory data covers such substance groups as: 1) the direct action greenhouse gases provided for in Annex A of the Kyoto Protocol (carbon dioxide (CO2), methane (CH4), nitrous oxide (N2O), hydrofluorocarbons (HFCs), perfluorocarbons (PFCs) and sulfur hexafluoride (SF6)); 2) precursors of greenhouse gases (carbon monoxide (CO), nitrogen oxides (NOx), non-methane volatile organic compounds (NMVOC); 3) any other greenhouse gases whose global warming values have been determined over a 100-year period by the Intergovernmental Panel on Climate Change (IPCC) and adopted by the Conference of the Parties; as well as sulfur oxides (SOx).

Given the difference in the intensity of climate impacts, greenhouse gas emissions and their absorption are calculated separately for each gas, in units of mass and carbon dioxide equivalent (CO2eq), depending on the global warming potential. In this case, the direct action emissions data of six greenhouse gases are systematized in the inventory of the six sectors of Annex A of the Kyoto Protocol, which qualify as «key emission categories», with a distinction from the absorption data of these gases, and are submitted to the Subsidiary Body in a standard format. reporting.

According to Part 3, 4 Article 3, Part 1, Article 7 of the Kyoto Protocol, the Parties shall also provide the necessary additional information as part of the annual national inventories and national communications. The additional information provided by Ukraine under these requirements relates to the following data: 1) the volume of emissions and sequestration of forest ecosystem reservoirs resulting from activities in the LUCULF sector, according to PP. 3, 4 Art. 3 of the Protocol; 2) the holdings of carbon units; 3) changes in the national greenhouse gas assessment system; 4) changes in the national registry of carbon units; 5) minimizing negative impacts (Prokhorenko, 2012).

Another confirmation of the interaction of the above international agreements and conventions in the field of environmental accounting is the provision of the Aarhus Convention and the Protocol on Pollutant Emissions and Transfer of 21 May 2003 that information on the state of the environment and sources of emissions should be communicated to the public.

In Art. 1 of the Protocol states that its purpose is to increase public access to information through the creation of consistent, integrated, nationwide emission and transfer registers (ETN) that could facilitate public participation in environmental and environmental decision-making. prevention of pollution and its reduction.

Under this Protocol, each Party shall establish and maintain a publicly available national pollutant emission and transfer register that is: (a) maintained separately for specific point source reporting facilities; b) contains data on diffuse sources; c) if necessary, kept separately for specific pollutants or wastes; d) covers different environmental components, distinguishing between emissions into air, land and water; e) contains information about the transfer; (e) It is based on the periodic reporting; (g) contain standardized and timely submitted data, a limited number of standardized reporting thresholds and, if available, a limited number of confidentiality provisions; (g) is logically consistent and user-friendly and accessible to the public, including in electronic form; h) involve the public in its development and modification; and (i) is a structured, 
computerized database or several aggregated databases maintained by a competent authority.

Each Party shall also ensure that the data contained in the register is submitted in both aggregated and detailed form so that emissions and transfers can be searched and determined by: (a) the facility and its geographical location; b) type of activity; (c) the owner or operator and, where appropriate, the company; d) contaminants or waste, where appropriate; e) every component of the environment to which the pollutant is emitted; and ( $\mathrm{f}$ ) the destination of the transfer and, where appropriate, disposal or disposal of waste.

To keep a proper inventory of the emissions, the owners or operators of the sites to be reported shall prepare and submit to the competent authority of the Party the following information on specific sites:

a) name, mailing address, geographical location and type or activities of the reporting entity, as well as the name of the owner or operator and, where appropriate, the name of the company;

b) name and identification number of each pollutant to be reported;

c) amount of each pollutant that is required to be reported to the facility into the environment during the reporting year, both as a whole and by emissions into the air, water or land, as well as underground injection;

d) or: 1) amount of each pollutant to be reported transferred beyond the site during the reporting year, with a distinction between the quantities transferred for disposal and disposal, and the name and address of the object to which the transfer occurred; or 2) amount of waste to be reported transferred beyond the site during the accounting year, with a distinction between hazardous waste and other waste, for any recovery or disposal operation with the appropriate « $\mathrm{R} »$ or $« \mathrm{D} »$ marking if waste is assigned for the disposal or disposal, and, in the case of transboundary movement of hazardous waste, the name and address of the waste disposal or disposal entity and the actual disposal or disposal site to which the transfer took place;

e) amount of each pollutant in the wastewater for which reporting is required has been carried beyond the site during the reporting year; and

f) type of methodology used to obtain the information, indicating whether that information is based on measurements, calculations or estimates.

In fact, it is this Protocol that is the first legally binding international instrument on pollutant emission and transfer registers, and its objective is to make publicly available information on air, water and soil emissions.

Today, the Protocol defines the criteria for submitting information on environmental pollutants based on international organizations such as Food and Agriculture Organization of the United Nations (FAO), Eurasian Economic Commission of the United Nations (EECUN), the World Bank, Eurostat, Organisation for Economic Cooperation and Development (OECD), International Energy Agency (IEA), and more.

For example, the Food and Agriculture Organization of the United Nations database (FAOSTAT) contains a rather informative set of indicators that characterize the environment. This organization focuses on greenhouse gas emissions research. In addition, it publishes regional statistical yearbooks on a wide range of issues, including the use of natural resources in agriculture, environmental pollution, biodiversity and 
climate change (FAO Statistical, 2015; FAO Statistical, 2016-2017; FAO Statistics, 2018)

The FAOSTAT database analysis identified three sections that characterize the environmental status of FAO UN member countries: emissions - agriculture; emissions - land use; agri-environmental indicators.

Agro-environmental indicators include indicators that characterize climate and air change, energy, fertilizers, land, livestock, pesticides, soil, water, emissions, and the intensity of emissions.

The sections on emissions - agriculture and emissions - land use contain information according to agricultural sectors, land categories and types of emissions.

An analysis of the World Bank's statistical database revealed a list of 112 environmental indicators (Environment. The World Bank, 2018). Data are presented in 263 countries. The study of this database made it possible to reveal reports on such 8 blocks of the environmental sphere as: lease payments for the use of natural resources; adjusted net savings on a number of items (mineral depletion, consumption of fixed capital, etc.); biodiversity and especially protected areas; air pollution; land and forest resources; renewable energy; use of natural resources; climate and more.

The World Bank collects information on the state of the environment, since fresh water, clean air, water resources are the basis of socio-economic development of the territories (Environment. The World Bank, 2018). The given information base is quite informative and allows to conduct interstate correlation of ecological status.

Organisation for Economic Co-operation and Development (hereinafter referred to as the OECD) is also involved in environmental security studies. The OECD Environmental Outlook to 2050. The Consequences of Inaction publishes forecasts for the state of the environment by 2050. To improve the picture, it is proposed to step up work on the following environmental areas: climate change, biodiversity, water resources and the impact of pollution on health (OECD Environmental Outlook to 2050, 2018).

\section{Problems of realization of measures for the implementation of environmental accounting in Ukraine}

In addition, the OECD has its own database of environmental indicators. It covers 13 areas such as air and climate, air and health, water, waste, mineral, forest and land resources, environmental policy, green growth and other areas.

Another system of indicators characterizing the environmental security of a number of countries is presented in the UNDP, including in tonnes of carbon dioxide emissions per capita; depletion of natural resources, as a percentage of gross national income; the percentage of the population living on degraded land; major energy sources, fossil fuels, as a percentage (OECD. Stat, 2019).

An analysis of the data provided by the International Energy Agency shows that one of the key areas of the organization is to work on environmental awareness. This activity expands the international understanding of possible solutions to climate change, as well as worldwide engagement through the collaboration of major manufacturers and consumers to develop alternative scenarios to address common environmental issues. The website of the International Energy Agency contains the collection of $\mathrm{CO} 2$ 
emissions from combustion. The data are presented in terms of the following groups: $\mathrm{CO} 2$ emissions from fuel combustion; $\mathrm{CO} 2$ emissions from fuel combustion by types: coal, oil, gas, oil for maritime transport, aviation fuel; $\mathrm{CO} 2$ emissions by sector; total primary energy supply; $\mathrm{CO} 2$ emissions to the total primary energy supply; per capita emissions by sector; CO2 emissions per capita, etc. (Global Assessment, 2019).

In order to improve public access to environmental information and thus contribute to the prevention and reduction of pollution in the long term, a European Pollutant Emission and Transfer Registry (PRTR), which is an ecological database or a description of the potential chemical hazard, has been introduced in the EU. substances and / or pollutants discharged into the atmosphere, discharged into the water and soil and transferred from one or another territory for processing or disposal.

PRTR includes information on the following: (a) who generates potentially harmful emissions and transports the waste to various environmental components; b) what pollutants are emitted and transported; c) how much is emitted or transported over a specific period of time; d) how the emissions and transportation of pollutants are distributed geographically, etc.

Having ratified the Protocol on Pollutant Emissions and Transfer Registers on February 3, 2016, Ukraine has committed to implement a nationwide public electronic system for pollutant emission inventories and subsequently join the European E-PRTR system.

The EU's experience on this issue shows that the recording of emission sources (installations), as well as the monitoring, reporting and verification of emissions (primarily carbon dioxide as the major by volume), is carried out for installations included in the emissions trading scheme in accordance with Directive 2003/87/EU and using the approaches established by the EU Commission Regulations: No 920/2010 on a standardized and secure system of registries; No. 691/2011 on the European System of Ecological and Economic Accounts; No. 600/2012 on the verification of greenhouse gas and tonne-kilometer reports and the accreditation of verifiers, and No. 601/2012 on the monitoring and reporting of greenhouse gas emissions, as well as the reporting of such emissions for the maintenance of the European Pollutant and Pollutant Release Register (E-PRTR), in accordance with Regulation (EC) No 166/2006 of the European Commission on the establishment of the European Pollutant Release and Transfer Register and amending Directives 91/689/EEC and 96/61/EC and Regulation (EC) No 1907/2006 on Registration, Evaluation, authorization and restriction of chemical echovyn and preparations (REACH), establishing the European Agency for chemical substances and preparations. Moreover, both reporting systems have limit values for the inclusion of sources / installations in the reporting system - 25 thousand tons of CO2 and 100 thousand tons of $\mathrm{CO} 2$, respectively.

Due to the setting of these limits, as well as the limitations of the specified directives and regulations by certain activities, such reporting does not cover all sources of emissions that are necessary to reduce anthropogenic greenhouse gas emissions. That is why the EU has a decision 280/2004/EU on a mechanism to control the Community's greenhouse gas emissions and to implement the Kyoto Protocol.

The issue of the exchange of information on pollutant emissions is based on Council Decision 97/101/EU of 27 January 1997 on the establishment of reciprocal exchange of 
information and data from networks and individual stations measuring atmospheric air pollution within Member States.

In addition, under the terms of the Energy Community Accession Treaty as part of the implementation of Directive 2010/75/EU on Industrial Emissions (Integrated Pollution Prevention and Control), the Government of Ukraine also has to submit data on emissions of pollutants from large combustion plants from 2018, (TPS, CHP plants, large boiler plants) to the Energy Community Secretariat.

It is established that in order to fulfill these obligations, the Government of Ukraine has today adopted the Decree No. 825-p of November 7, 2018 «On approval of the Concept of creation of the national automated system «Open Environment», which provides for the creation of such components of the said system, as the geo-portal of environmental data (with geoinformation / coordinate binding of data on the mapping service) with subsystem of environmental monitoring, emission register and pollutant transfer, geoinformation a register of territories and objects of the nature reserve fund, which will include metadata on the environmental status of other holders of information resources, analytical materials, statistical information, information materials of public environmental organizations (with the consent).

The purpose of creating an automated «Open Environment» system is to: 1) give citizens free access to environmental information and environmental risks/threats to safe living; 2) modernization of public administration and digitization of the process of providing administrative services in the field of environmental protection within the framework of integrated implementation of e-government mechanisms and informatization of state and local self-government bodies in the field of environmental protection, rational use, reproduction and protection of natural resources.

The Concept is expected to be implemented in 2018-2020, and the process is still ongoing.

However, will it solve all existing problems of implementing such a system? In the course of the research conducted by the authors of this work, a number of practical problems were identified during the implementation of the existing legal requirements for environmental accounting, in particular: substances into the ambient air by stationary sources, which led to the lack of reliable data on the number of such entities, and therefore the proper payment of environmental tax; 2) the absence of statutory deadlines for enterprises to inventory pollutants and submit relevant reports to the bodies of the Ministry of Ecology and Natural Resources of Ukraine; 3) absence of a single accounting base of water users who have permits for special water use, etc.

\section{Conclusions}

The analysis of the legal bases of environmental accounting as a means of defining indicators of the environmental component of sustainable development, conducted in the course of this study, showed that the system of environmental accounting as a single information base continues to evolve at the international, European and national levels, so to speak about it as a means early. However, today, according to the UN, the ecological and economic component of sustainable development is still in considerable dissonance, reflecting directly on human health and 
the rapid pace of climate change. This may mean the following: either the environmental accounting system is not showing reliable data and the pollution levels are continuing to increase, and therefore the existing public administration measures in this area are insufficient, or the planet is shifting due to long-term man-made load and natural processes. to a new stage in its evolution.

The problems identified by us in the legal support of environmental accounting in Ukraine show its imperfection due to the lack of reliable data on the number of environmental pollutants, which directly affects the results of environmental monitoring and filling the state and local budgets with an environmental tax, the funds of which, in the future, used for environmental measures.

In this regard, we emphasize that in order to recognize environmental accounting as an effective means of identifying indicators of the environmental component of sustainable development, each state of the world must conduct an internal audit of existing legislation, its completeness and interconnection, which will allow to build a single effective system. environmental accounting, the information of which will allow us to take adequate and timely measures of environmental management.

\section{References}

Accounting for Freshwater Quality in India. (2007). Retrieved from: https://unstats.un.org/unsd/envaccounting/ceea/archive/Water/India GAISP Freshwater qual ity.pdf.

Bobyleva S.N., Makeenko P.A. Index of sustainable development of Russia (ecological and economic aspects). (2001). Moscow: TSPR.

Brinchuk M.M. (1998). State statistical recording and reporting. Moscow: Lawyer.

Central basis of the System of natural and economic accounting. (2017). The UN. New York.

Concept and methods of environment statistics. Statistics of the natural environment. Technical report. (1992). Epy UN, Tew York, ST/ESA/STAT/SER.F/57.

Concepts, sources et methodes du Systeme des comptes de l'environnement et des ressources du Canada. (2006). Retrieved from: https://www150.statcan.gc.ca/n1/fr/pub/16-505-g/16-505-g1997001fra.pdf?st $=\mathrm{qCt} 6 \mathrm{QK} 3$

Council of Europe Parliamentary Assembly Recommendation on environmental accounting as a tool for sustainable development (2004). Retrieved from: https://www.coe.int/T/r/Parliamentary_Assembly/[Russian_documents]/[2004]/[Paris 2004]/R ec.1653-Rus.asp\#TopOfPage.

Environmental Audit Program Design Guidelines for Federal Agencies. (1997). Retrieved from: https://www.epa.gov/sites/production/files/documents/envaudproguidemas.pdf.

Extended Input-Output Model for Energy and Greenhouse Gases. (2011). Retrieved from: https://circabc.europa.eu/sd/a/7b6655a2-ed7d-4a7f-9eb940d154b94f40/09\%20DE\%20249\%20I O\%20GHG.pdf.

FAO Statistical Pocketbook. World food and agriculture. (2015). Retrieved from: http://www.fao.org/3/ai4691e.pdf.

FAO Statistics. World Food and Agriculture. Statistical pocketbook. (2018). Retrieved from: http://www.fao.org/3/CA1796EN/ca1796en.pdf

FAO. Statistical Programme of work: 2016-2017. (2017). Retrieved from: http://www.fao.org/3/ai3592e.pdf

Framework for the development of environment statistics. (1985). The UN, New York, ST/ESA/STAT/SER.F/78.

Garcia S.M., Staples D.J., Chesson J. (2000). The FAO guidelines for the development and use of indicators for sustainable development of marine capture fisheries and an Australian example of their 
application. Ocean \& Coastal Management, 43 (7), 537-556. Retrieved from: https://www.sciencedirect.com/science/article/pii/S0964569100000454.

Global Assessment of Human-induced Soil Degradation (GLASOD). (2019). Retrieved from: https://www.isric.org/projects/global-assessment-human-induced-soil-degradation-glasod.

Golovko, L., Yara, O., Kutsevych, M., Hubanova, T. (2019). Environmental Policy Integration in Ukraine and the EU European Journal of Sustainable Development, Volume 8, № 3, 221-227

Gryuning, H., Coen, M. (2000). International standards of financial reporting. Practical guide. Moscow: ICAR; World Bank.

Hrytsenko, Olena I. (2016). Ecological recording: identification of prospects and basic principles of implementation. Economy and society, 2: 678-683. (In Ukraine)

Integrated environmental and economic accounting. Operational manual. (2001). (Methodical research, Ser. F, No. 78). New York: The UN.

International financial reporting standards. (1998). Moscow: Firm «Askeri».

Jones, Michael J. (2019). Accounting for the environment: Towards a theoretical perspective for environmental accounting and reporting. Accounting Forum, 34:2, 123-138. Retrieved from: https://doi.org/10.1016/i.accfor.2010.03.001.

Kirsanova T.A., Kirsanova E.V., Lukyanikhin V.A. (2004). Environmental controlling - an instrument of ecomanagement. Sumy: Cossack val st.

Knyazev V.G., Chernik D.G. Tax systems of foreign countries. (1997). Moscow: YUNITI.

Kolesnik S.I. (2000). The necessity and problems of development of ecological statistics. The problems of statistics. Kyiv: Research statistics Institute of Ukrainian State Statistics Service.

Kovalev V.V. (1997). Accounting standardization: an international dimension, Accounting, 11, 20-21.

Kozhukhova, O.S. (2012). Environmental recording and environmental controlling: interconnection and integration. Management of economic systems: Electronic scientific journal. Retrieved from: http://www.uecs.ru/uecs-39-392012/item/1165-2012-03-26-11-23-42. Hm. (In Russian)

Krasnova I.O. (1992). Ecological law and governance in the U.S. Moscow: Academy of Baikal.

Kuik, Onno J., Verbruggen, H. In search of indicators of sustainable development. (2012). Retrieved from: https://books.google.com.ua/books?hl=uk\&lr=\&id=9H9WAwAAQBAJ\&oi=fnd\&pg=PP6\&dq =indicators + of + sustainable + development\&ots $=$ MHSx KsnMl\&sig $=\mathrm{vxkB}$ eAhla0EFornhTlauz PCCFo\&redir esc $={ }_{\mathrm{y}} \#_{\mathrm{v}}=$ onepage\&q $=$ indicators $\% 20 \mathrm{of} \% 20$ sustainable $\% 20$ development $\& \mathrm{f}=$ false $_{\mathrm{f}}$

La Revue du CGDD: Nature and the Wealth of Nations. (2015). Retrieved from: http://temis.documentation.developpement-durable.gouv.fr/docs/Temis/0083/Temis0083488/22322.pdf.

Ladychenko V., Yara O., Uliutina O., Golovko L. (2019). Environmental liability in Ukraine and the EU. European Journal, Volume 8, № 2, 261-267.

Ladychenko, V., Golovko, L. (2018). The Right of Access to Environmental Information in Ukraine and the EU. European Journal of Sustainable Development, Volume 7, № 3, 455-459.

Ladychenko, V., Yara, O., Golovko, L., Serediuk, V. (2019). Groundwater management in Ukraine and the EU. European Journal of Sustainable development, Volume 8, № 1, 31-39.

Larrinaga-Gonzalez C., Bebbington J. (2001). Accounting change or institutional appropriation? - A case study of the implementation of environmental accounting. Critical Perspectives on Accounting, 12 (3), 269-292. Retrieved from: https://doi.org/10.1006/cpac.2000.0433.

Lazareva L.P., Milovetz V.M. (2008). Environmental indicators. Vologda readings, 3: 173-178.

MacGillivray A., Zadek S. (1995). Accounting for change: indicators for sustainable development. London: New Economics Foundation.

Malysheva, Nataliia R. (2018). State registration of units that are the scourge of the environment. In the Great Ukrainian legal encyclopedia: 20 volumes. T. 14: Ecological law. Kharkiv: Law, 231-234.

Manual for Air Emissions Accounts. (2015). Retrieved from: https://ec.europa.eu/eurostat/documents/3859598/7077248/KS-GQ-15-009-ENN.pdf/ce75a7d2-4f3a-4f04-a4b1-747a6614eeb3.

Matveeva, E.M. (1998). International accounting (GAAP and IAS). Moscow: Publishing house «Dis».

Nesterenko O.O. (2017). Sedimentary development evaluation indicators and their effect on integrated reporting indicators. Scientific berald of Uzhogorod National University. Series: International Economic Relations and the World Economy is an economic research journal, 15: 2, 44-50. 
O’Donovan G. (2001). Environmental accounting: Good for business, bad for the planet? Interdisciplinary environmental review. Retrieved from: https://www.inderscienceonline.com/doi/abs/10.1504/IER.2001.053888.

OECD Environmental Outlook to 2050. The Consequences of Inaction. (2018). Retrieved from: https://www.oecd.org/g20/topics/energy-environment-greengrowth/oecdenvironmentaloutlookto2050theconsequencesofinaction.htm.

OECD. Stat. (2019). Retrieved from: http://stats.oecd.org/.

Prokhorenko, Kateryna A. (2012). Legal regulation of anthropogenic greenhouse gas emissions recording and their absorption under the legislation of Ukraine. Bulletin of Taras Shevchenko National University. Legal science, 90, 82-86.

Pyrikov O.V. (2013). Indicators and systems of sustainable development: the theory and practice. Productive economy. Retrieved from:http://www.economy.nayka.com.ua/?op=1\&z=4026. (In Ukraine)

Schaltegger, S., Burritt, R. (2000). Contemporary Environmental Accounting. London: Routledge. Retrieved from: https://doi.org/10.4324/9781351282529.

Serov G.P. (1999). Environmental audit. Educational and practical guide. Moscow: Exam.

Shapiguzov S.M. (1997). Accounting system of environmental activities of the enterprise. Environmental accounting and audit. Moscow: FBK-PRESS.

Steurer R., Hametner M. (2010). Objectives and Indicators in Sustainable Development Strategies: Similarities and Variances across Europe. Sustainable Development, 21 (4). Retrieved from: https://onlinelibrary.wiley.com/doi/abs/10.1002/sd.501.

The World Bank. Environment. (2018). Retrieved from: https://data.worldbank.org/topic/environment.

Umweltökonomische Gesamtrechnungen. CO2 content of German import and export goods, 2000 - 2010. $\begin{array}{llll}\text { (2014). Knyazev, } & \text { V.G. }\end{array}$ https://unstats.un.org/unsd/envaccounting/ceea/archive/Air/Germany co2 2014.pdf.

Waste Account, Australia, Experimental Estimates. (2013). Retrieved from: https://www.abs.gov.au/Ausstats/abs@.nsf/0/B3B9F11D331B0EADCA257B16000E1987?Ope nDocument

Yara, O., Uliutina, O., Golovko, L., Andrushchenko L. (2018). The EU Water Framework Directive: Challenges and Prospects for Implementation in Ukraine. European Journal of Sustainable Development, Volume 7, № 2, 175-182

Yegorova, Yelena N. (1995). Comparative analysis of foreign tax systems and development of taxation in Russia, Tax updates, 11, 25-29. 